\title{
Mileposts in the Development of Salutogenesis
}

\author{
Bengt Lindström
}

\section{First Encounter}

It was a sunny and windy afternoon in the Spring of 1987. I was waiting for a group of guests of Public Health Officials on the pier of the Nordic School of Public Health. They were arriving quite spectacularly on a 19th-century steamship, "Bohuslän," used at special occasions by the City of Göteborg. The sea was quite rough, and it took a while to dock and land the old, tall, and narrow ship. I had time to scan the many familiar faces of colleagues and friends on board but among them was a new face.

I greeted my friends and walked up to the new person who looked a bit pale and shaky and relieved getting on firm land; he said: "Hi, I am not used to the sea because I come from the middle of the Negeb desert and the Beersheva University in Israel, I am Aaron Antonovsky."

This was my first encounter with Aaron Antonovsky (Fig. 2.1), the father of salutogenesis. As a welcome, he handed me a signed copy of his latest book, fresh from the printers, titled "Unravelling the Mystery of Health." It was the beginning of a friendship that would last until his sudden death seven years later.

\section{My Understanding of "Salutogenesis" Before Antonovsky}

As for so many others, the salutogenic thought was not completely new to me as such, but we did not have the concepts and words to specify what it was about until Aaron Antonovsky conceptualized his model. My salutogenic journey started before I met with him. I trained as a physician in Finland and specialized in pediatrics; I wished and hoped pediatrics could have been called child health and move beyond the traditional health-disease axis, but this was the late 1960s and early 1970s; in Finland, the prime time for "hardcore biomedical science."

Our teachers were decidedly ignorant of other entry points to medicine and what went on in the community outside of

B. Lindström $(\square)$

NTNU Center for Health Promotion Research, Norwegian University of Science and Technology, Trondheim, Norway

e-mail: bengtblind@hotmail.com

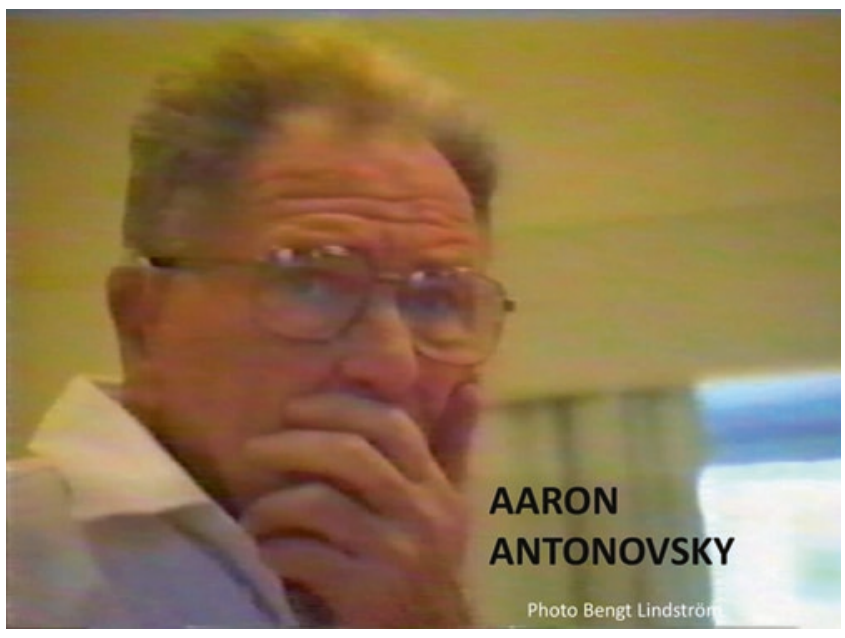

Fig. 2.1 Aaron Antonovsky, teaching at the Nordic School of Public Health in 1992

the hospitals. I never understood why you learnt anatomy like reading a telephone book or why you were trained in understanding only the somatic growth of a child, integrating neither the mental and social nor spiritual dimensions into a wholeness. During my specialization, I moved to Sweden, where pediatrics was more open to the community; meaning in your training, you met healthy children and their families in Child Wellbeing Clinics. Also, in Sweden, child mental health services were provided through child and adolescent psychiatry.

Although I loved to work with children and families and was good at it, there was always that longing for a more direct approach to health. Much later, already 10 years into medicine, came the event that finally changed my professional orientation. I was in charge of a group of children with cystic fibrosis, a genetic disease that at that time lead to infections, malnutrition, and usually a premature death due to severe lung infections.

One morning I met a family well-known to me; they had already lost one child to the disease, and this day the younger 
sister - 17-year-old Maria ${ }^{1}$ - also suffering from cystic fibrosis, was at my surgery. But that day, the front page of her records had a new handwritten note: marked in red were the letters PSEUDOMONAS!!! This meant she had the infection everybody in the care of cystic fibrosis patients feared, an infection we could not master, which would eventually lead to her death. I was young at the time and not yet experienced with death. I was thinking of what to say about her future when she walked into the room. Coughing, wasted and frail she came toward me. I was about to start when I realized her eyes were shining, her cheeks blushing, and she was smiling. I stopped myself and asked "Maria - what is it?" She looked at me, gave me a broad smile and said: "Bengt, I am in love. I want to get married, and I want to have children!"

Because of her sister, she knew very well where everything was going but still, in the face of death, she was talking about life, love and having a family. Eventually, she did not make it, but it left me forever thinking of how this was possible, that what she talked about contradicted all I had learnt in medical school; this is where my journey toward salutogenesis began. Antonovsky would have said, "You idiot (as he said to himself), you were looking in the wrong direction!"

A few years later, because of Maria, I broke out of the Clinics, and in 1984, I went into public health research and training at the Nordic School of Public Health (Nordic School of Public Health), serving five countries in interdisciplinary postgraduate training and research. These were the years when the World Health Organization (WHO) Health for All Strategy was launched; WHO stepped beyond health care into community health and launched the Ottawa Charter for Health Promotion in 1986, which advocated a structural approach to implement health promotion.

My years at Nordic School of Public Health were intensive and rewarding. Of great significance to me, Aaron Antonovsky was a regularly returning visiting scholar at the school from 1987 to 1994 , active and engaging in teaching and guiding seminars. It would not take long before he was appointed Honorary Professor at the Nordic School at the same time as Ilona Kickbusch, the then Health Promotion Director of WHO.

I took special care to accompany him during his visits to the School, and I eagerly attended his lectures and seminars, taking detailed notes. As a result, I have a collection of his lectures spanning 7 years and several hours of his presentations on video recordings. I admired the way he presented salutogenesis concepts in the classroom; and ever since, I have tended to emulate his pedagogic approach and his use of drawings to illustrate key ideas.

He was teaching at the European Training Consortium Course at the school when he agreed to read the manuscript

\footnotetext{
${ }^{1}$ The name has been changed to protect privacy and confidentiality.
}

of my first publication on salutogenesis, dealing with the amelioration of children experiencing family breakdown. The emphasis was on seeing divorce through the perspective of the child and as a process, not as one point-in-time event. Three questions are important from a salutogenic perspective: How do adverse life events affect one over time? How do adverse events (here related to divorce) unfold from the perspective of the target group (here the child)? What is needed to steer a constructive process? My conclusion was that it is not the life event of "divorce" as such that is important. The important thing is what conditions prevail before and after, how the whole process is managed, how does the child perceive it, and how does it make sense to the child?

Discussing my paper, Antonovsky approved of my line of thought. This was 1993; he mentioned he was going to participate in an important meeting at WHO in Copenhagen, where he was to hold a seminar attended by leading health promotion experts, on how salutogenesis could be used as a framework for health promotion. It was a shock when, shortly after the Copenhagen meeting, I received a fax from Aaron reading, "Dear Bengt, I have a malignant cancer, going into care tomorrow, pray for me." He died days later. The loss of Antonovsky paralyzed his closest research networks for a long time. It was also the end of his Salutogenesis Newsletters, which at the time were the primary source of news about salutogenesis developments globally.

His WHO presentation was published in Health Promotion International after his death (Antonovsky, 1996). This landmark work concluded:

\begin{abstract}
With great respect for the concept of health promotion (and for those committed to it), I have none the less been highly critical, in emphasizing that the basic flaw of the field is that it has no theory. The salutogenic orientation has been proposed as providing a direction and focus, allowing the field to be committed to concern with the entire spectrum of health ease/dis-ease, to focus on salutary rather than risk factors, and always to see the entire person...
\end{abstract}

Within a few years, Antonovsky's posthumously published call to action was well heeded. It is not an exaggeration to proclaim this single publication as the catalyst - the milepost - for the burgeoning of salutogenesis scholarship.

\section{A Chronology of Key Developments After 1996}

This chronology has a decidedly personal cast since I am aware of salutogenesis developments mainly through my involvement. My first organizational responsibility outside the Nordic School of Public Health was as the Secretary General of the European Society of Social Pediatrics (ESSOP). At the same time, I took a similar position in NOBAB (Nordic Network for Children's rights and needs in 
health care) concerned with implementing the Convention on the Rights of the Child within Health Care.

One key member of ESSOP whom I worked with for a long time on many health promotion projects was Concha Colomer (1958-2011) from Valencia, Spain. Concha holds a special place in the development of salutogenesis scholarship as a cofounder of a postgraduate training summer course in health promotion that has salutogenesis as a shaping principle. The course is run by the European Training Consortium in Public Health and Health Promotion - ETC-PHHP (the founding partners were the Nordic School of Public Health, the Valencian School of Public Health, the Andrija Stampar School of Public Health in Croatia, and the Liverpool Department of Public Health). Since 1991, 782 students have been trained, coming from over 60 different countries. In a separate chapter in this Handbook, Vaandrager and colleagues describe details of the history and activities of the course.

The autumn following Antonovsky's death, I visited the school of Public Health in Granada, Spain, to participate in a health promotion seminar lead by Erio Ziglio, the WHO European Director of Health Promotion. We discussed the need for greater emphasis on salutogenesis in health promotion research and training, and in 1995, I set up courses on health promotion and salutogenesis at the Nordic School. I was in charge of the course on salutogenesis for over 15 years. In 2007, the salutogenesis course evolved to become the International Seminar on Salutogenesis of the Global Working Group on Salutogenesis - GWG-Sal which I chaired for a decade (more about GWG-Sal later).

I had the opportunity to introduce salutogenesis at the first Nordic Health Promotion Research Conference at the University of Bergen in 1996, where Maurice Mittelmark was the host. Salutogenesis has featured on the program at all subsequent Nordic conferences, the most recent being the Ninth, held in 2019 at Roskilde University.

About the same time, I was invited to a Swedish Research Council seminar on the status of research on salutogenesis. Attending were Marianne Cederblad and Kjell Hansson, who were among the first to research salutogenesis in Sweden (they also hosted Antonovsky's sabbatical in Lund in 1987). Also participating in the seminar was Olle Lundberg, who together with Maria Nyström Peck had developed the three-question SOC scale. The consensus emerging from the seminar was that research on measuring the SOC was too meager. I wished to contribute to the needed research and recruited Monica Eriksson to work with me on the task. Monica had written her master's thesis on salutogenesis in Finland, where Guy Bäckman had introduced salutogenesis to Finnish academia. With me as her advisor, Monica undertook her PhD at Åbo Akademi University Vasa on the sense of coherence, which resulted in a series of pub- lications that have become classic papers in the field (Eriksson, 2007).

There were many other salutogenesis developments at about the same time. Maurice Mittelmark was the President of the International Union for Health Promotion and Education - IUHPE. He was determined to pave the way for salutogenesis in health promotion, and in 2007, the IUHPE established GWG-Sal, with me as its founding Chair.

A bit earlier, I worked to infuse salutogenesis into a 6-year European Union project to establish a framework for a European Masters in Health promotion (EUMAHP, 19982004). The project included many prominent health promotion scholars from the continent, among them was Georg Bauer, who was to succeed me as head of GWG-Sal when I retired in 2017.

In a related EU project aiming to develop health promotion indicators (the EUPHID project), Bauer led the team that constructed an influential framework for research indicators, which had an explicit salutogenesis orientation (Bauer et al., 2006).

In 2005, I became Research Director for Health Promotion at Folkhälsan, an old established Finish NGO that was involved in population health and community development practice and research. Monica Eriksson joined me on the research team. The Folkhälsan position allowed me, for the first time in my career, to pull my thoughts together and focus entirely on my work on salutogenesis.

Monica and I conducted systematic reviews, with rigorous inclusion and exclusion criteria, of research that had used Antonovsky's salutogenesis framework up to that time (Eriksson, 2007). We also built an open-access database on salutogenesis to serve researchers all over the globe. During our 5 years at Folkhälsan, we helped to consolidate international collaboration. For example, we worked closely with two Norwegian collaborators to establish significant salutogenesis infrastructure in Norway. Geir Espnes was the founding director of the Center for Health Promotion Research at the Norwegian University for Science and Technology in Trondheim, and Nina Mjosund reconfigured the Buskerud Regional Psychiatric Services in Norway, resulting in a unique entry point for salutogenesis in mental health care.

From 2007 on, the IUHPE became a principal arena for salutogenesis, which has had a significant place in IUHPE global and regional conferences ever since. This helped to expose health promotion practitioners and researchers to salutogenesis, but a dedicated meeting place was also needed for people immersed in salutogenesis.

Responding to the need, we organized the First International Seminar on Salutogenesis in Helsinki in the Spring of 2008, with about 150 researchers and practitioners participating from Asia, Europe, and North America. Among them was Shifra Sagy (whose PhD advisor in Israel had been 
Antonovsky), who gave a brilliant presentation on the early days of salutogenesis.

At the end of 2008, we organized the first meeting of GWG-Sal at Nordic School of Public Health, with founding members Sagy, Mittelmark, Bauer, Lindström, Eriksson, Corey Keyes (United States), Lenneke Vaandrager (the Netherlands), and Jürgen Pelikan (Austria).

The Second International Seminar on Salutogenesis was held in 2009, at Folkhalsan in Helsinki. The same year, the GWG-Sal members participated in a seminar on resilience in London, and as a group, presented salutogenesis and its relationship to resilience to the audience. We also held our second GWG-Sal meeting in London, and at that meeting, we agreed to produce a handbook on salutogenesis, which was published by Springer (Mittelmark et al., 2017).

The Third International Seminar on Salutogenesis was arranged at the IUHPE World Conference in Geneva in 2010, where we launched salutogenesis on a broad scale to the global health promotion community. The same year we introduced our work at the WHO Global Conference on Health Promotion in Nairobi. All IUHPE World Conference scientific programs have since had input from GWG-sal, leading to many salutogenesis subplenary, paper, poster sessions, and workshops, during the 2013, 2016, and 2019 conferences.

In 2010, we published The Hitchhiker's Guide to Salutogenesis: Salutogenic Pathways to Health Promotion (Lindström \& Eriksson, 2010). This was first published in English, and at the time of writing, the book is available in eight languages: English, Spanish, Catalan, French, Norwegian, Italian, German, and Polish.

In 2011, the International Seminar on Salutogenesis was arranged at University West in Trollhättan, Sweden, where Monica Eriksson was later appointed Professor. The same year, I was appointed Professor of Salutogenesis (the first professorship with this title) at the Norwegian University of Science and Technology in Trondheim, Norway (where I continued until my retirement in 2017). The GWG-Sal operation moved with me to Trondheim, where Geir Espnes had established a new Center for Health Promotion Research. Geir launched a series of International Health Forum biannual conferences (2012-2018), wherein a dedicated part of the scientific program was the International Seminar on Salutogenesis. On my retirement in 2017, Georg Bauer took over the leadership of the GWG-Sal at the newly founded Center on Salutogenesis at the University of Zürich in Switzerland.

Coincident with the inauguration of the Zürich center (by the President of the University), GWG-Sal launched the Society for Theory and Research on Salutogenesis - STARS (www.stars-society.org). The society was established as a home for academics interested in salutogenesis, reaching beyond the health promotion discipline to welcome other disciplines in the social science and biomedical sciences communities. The year 2017 was a boom year for salutogenesis; besides the activities just mentioned, the first edition of The Handbook of Salutogenesis was published as an openaccess publication of Springer Nature, edited by GWG-Sal members. In the short period since its publication, the handbook has risen to the top three Springer open-access publications globally, measured by the number of downloads. It was the popularity of the first edition that gave GWG-Sal members the motivation to start work on this second edition.

\section{Conclusion}

The first salutogenesis study was undertaken in the late 1960s and published in Antonovsky's books in 1979 and 1987. With his background in medical sociology, he related his salutogenic framework to the field of health, and he wished to foment a paradigm adjustment, from pathogenesis standing alone to pathogenesis and salutogenesis. He reasoned that the field of health promotion was fertile ground for such a shift. Where are we at this point? In a practical sense, the contents of this handbook answer the question. There seems to be no doubt that salutogenesis is thriving in its research, teaching and theory building.

Yet, salutogenesis is still in its infancy, a maturing construct, but with many unanswered questions that are posed in the concluding sections of many of this book's chapters. The final chapter of this handbook, coauthored by its GWG-Sal editors, addresses some of the critical issues that salutogenesis as an academic field must address to advance as transdisciplinary science, and hasten the paradigm adjustment that Antonovsky envisioned (Bauer et al. 2020).

\section{References}

Antonovsky, A. (1996). The salutogenic model as a theory to guide health promotion. Health Promotion International, 11(1), 11-18.

Bauer, G., Davies, J. K., Pelikan, J., \& Euhpid Theory Working Group and The Euhpid Consortium. (2006). The EUHPID Health Development Model for the classification of public health indicators. Health Promotion International, 21(2), 153-159.

Bauer, G. F., Roy, M., Bakibinga, P., Contu, P., Downe, S., Eriksson, M., ... Mana, A. (2020). Future directions for the concept of salutogenesis: A position article. Health Promotion International, 35(2), 187-195.

Eriksson, M. (2007). Unravelling the Mystery of Salutogenesis. Folkhälsan Research centre, Research Report 2007:1. Helsinki.

Lindström, B., \& Eriksson, M. (2010). The hitchhiker's guide to salutogenesis: Salutogenic pathways to health promotion. Folkhälsan Research Center.

Mittelmark, M. B., Sagy, S., Eriksson, M., Bauer, G. F., Pelikan, J. M., Lindström, B., \& Arild Espnes, G. (2017). The handbook of Salutogenesis. Springer Nature. 
Open Access This chapter is licensed under the terms of the Creative Commons Attribution 4.0 International License (http://creativecommons. $\mathrm{org} / \mathrm{licenses} / \mathrm{by} / 4.0 /)$, which permits use, sharing, adaptation, distribution and reproduction in any medium or format, as long as you give appropriate credit to the original author(s) and the source, provide a link to the Creative Commons license and indicate if changes were made.

The images or other third party material in this chapter are included in the chapter's Creative Commons license, unless indicated otherwise in a credit line to the material. If material is not included in the chapter's Creative Commons license and your intended use is not permitted by statutory regulation or exceeds the permitted use, you will need to obtain permission directly from the copyright holder. 